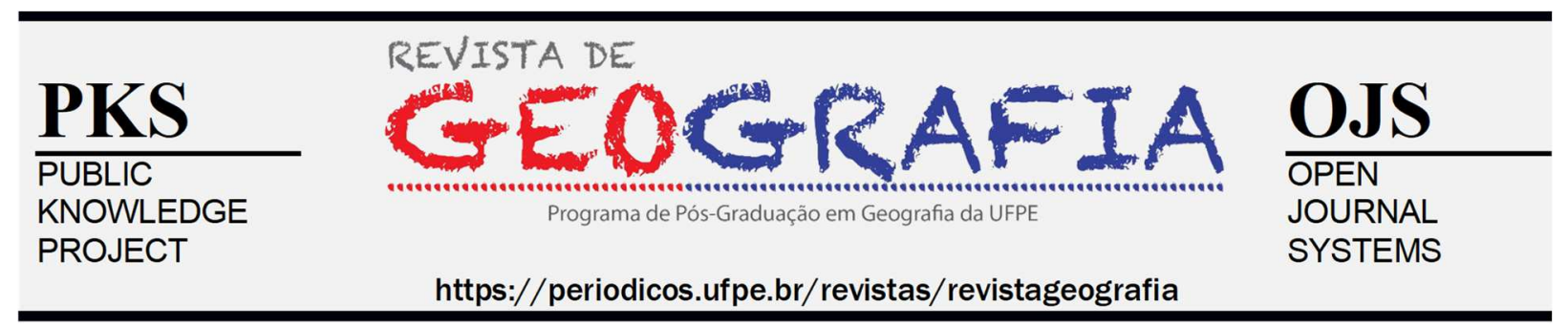

\title{
A DIMENSÃO AMBIENTAL PARA O ORDENAMENTO TERRITORIAL
}

\author{
Diêgo Souza Albuquerque ${ }^{1}$, Larissa da Silva Ferreira Alves ${ }^{2}$, Francisco do O' de Lima \\ Júnior $^{3}$, Maria Losângela Martins de Sousa ${ }^{4}$
}

1 Doutorando em Geografia pela Universidade Federal da Paraíba, João Pessoa/PB. E-mail: diealbuquerque07@gmail.com; https://orcid.org/0000-0002-0504-4972.

2 Dra. em Geografia, professora da Universidade do Estado do Rio Grande do Norte, Pau dos Ferros/RN. E-mail: larissaferreira@uern.br; https://orcid.org/0000-0003-2232-9539.

3 Dr. em Desenvolvimento Econômico, professor da Universidade Regional do Cariri, Crato/CE. E-mail: limajunior_economia@yahoo.com.br; https://orcid.org/0000-0002-6049-3893.

${ }^{4}$ Dra. em Geografia, professora da Universidade do Estado do Rio Grande do Norte, Pau dos Ferros/RN. E-mail: losangelaufc@gmail.com; https://orcid.org/0000-0003-3798-283X.

Artigo recebido em 29/01/2020 e aceito em 18/02/2021

\section{RESUMO}

O presente trabalho objetiva discutir a importância do meio ambiente para as políticas e ações de ordenamento territorial (OT). Parte-se do pressuposto de que a base ambiental é fator interveniente de grande relevância para políticas e ações de OT. Isso é percebido no conjunto das regulamentações legais que arbitram sobre o uso e exploração dos recursos ambientais do território. Para a construção do presente texto, fez-se um percurso teórico que envolve as compreensões de ambiente, questão ambiental e ordenamento territorial. Em seguida, realizou-se considerações acerca da política ambiental brasileira, analisando essa como mecanismo que serve ao OT, sendo respaldado em Steinberger e Abirached (2013) quando estas autoras discutem que a política ambiental é dotada de dimensão territorial, uma vez que essa possui contato direto com o território. A partir da pesquisa constata-se que a dimensão ambiental se torna cara para uma efetiva política de OT, ao passo que os instrumentos jurídicos que orientam e impõem restrições ao uso dos recursos ambientais do território se conformam, então, em uma política de base territorial, dado que os disciplinamentos são sob o território. Portanto, são medidas que orientam a execução de seu uso, regulação e proteção.

Palavras-chave: recurso natural; ambiente; território; política ambiental.

\section{THE ENVIRONMENTAL DIMENSION FOR TERRITORIAL ORDINATION}

\section{ABSTRACT}

The present work aims to discuss the importance of the environment for territorial planning policies and actions. It is based on the assumption that the environmental base is an intervening factor of great relevance for territorial planning policies and actions. This is seen in the set of legal regulations that refer to the use and exploitation of the territory's environmental resources. For the construction of this 
text, a theoretical discussion was taken by involving the understanding of the environment, environmental issue and territorial ordering. Then, considerations were made about the Brazilian environmental policy, analyzing it as mechanism that serve the territorial ordering, being supported by Steinberger e Abirached (2013) when these authors argue that the environmental policy has a territorial dimension, since this issue has direct contact with the territory. Based on the research, it can be seen that the environmental dimension becomes expensive for an effective territorial planning policy, while the legal instruments that guide and impose restrictions on the use of the territory's environmental resources conform, then, to a basic territorial policy, when we glance at that the disciplines are under the territory. Therefore, they are measures that guide the execution of its use, regulation and protection.

Key-words: natural resources; environment; territory; environmental policy.

\section{INTRODUÇÃO}

Na medida em que se percebeu a crescente degradação ambiental e as problemáticas na qualidade de vida da população, inicialmente nos grandes centros urbanos, motivados pelo uso e exploração inconsequente dos recursos naturais e das atividades industriais-produtivas, se viu, em escala planetária, manifestações preocupadas com os rumos que se estavam dando ao planeta Terra.

As problemáticas ambientais já eram discutidas, contudo, é realmente a partir do século $\mathrm{XX}$, com o alto desenvolvimento tecnológico angariado, que a agressividade ao meio ambiente se tornou insustentável. A partir de então, surge uma perspectiva dotada de uso racional dos recursos naturais, respeito aos elementos naturais, desenvolvimento com sustentabilidade, relação sadia do homem com o meio, ou ainda harmonia entre sociedade-natureza. Essas perspectivas elucidam um caráter urgente de revisão dos tratos da humanidade para com o ambiente.

No campo prático, em nível mundial, surgem inúmeras regulamentações jurídicas para disciplinar o uso do ambiente e de seus recursos. Atravessado pelas pressões mundiais, o Brasil vai instituindo suas políticas legais de cuidados com o meio ambiente. Essas políticas, ao passo que regulam o uso dos recursos, também regulam o uso do território. As mesmas são exemplos de estratégias de ordenamento do território, pois criam arranjos discursivos e práticos para a organização e manutenção da extensão territorial sobre sua jurisprudência, objetivando o uso racional dos elementos naturais, bem como na promoção da resolução de conflitos.

Nesse ínterim, a presente escrita tem por finalidade discutir a importância do ambiente para as políticas e ações de ordenamento territorial (OT), considerando o fato de que a organização do território necessita considerar sua base ambiental. Portanto, sendo importante 
compreender como se processa a dinâmica da paisagem, quais as potencialidades naturais, as limitações de uso e as diretrizes frente a capacidade de suporte das mesmas.

Metodologicamente, para este trabalho, foi desenvolvida a revisão bibliográfica para embasar a discussão proposta, utilizando autores como Dulley (2004), Porto-Gonçalves (2006), Araújo (2007), Mendonça (2009), Suertegaray (2009) e Custódio (2011) para o entendimento do meio ambiente e da questão ambiental efervescida pós segunda metade do século XX; CEOT (1988), Pujadas e Font (1998), Moraes (2005), Santos (2005), Haesbaert (2006) e Alves (2013) são discussões no tocante ao ordenamento do território, buscando identificar como o meio ambiente é incluso nas concepções teóricas dos autores. Além disso, foram feitas considerações sobre a política ambiental brasileira com foco na Política Nacional do Meio Ambiente (PNMA) de 1981, compreendendo essa como uma fiel articuladora da perspectiva ambiental no OT.

Para tanto, o trabalho se encontra organizado da seguinte maneira: introdução, adentrando a temática, apresentando o objetivo e justificativa do mesmo; a seção segunda, discutindo o que se entende por ambiente e questão ambiental; a seção terceira, sendo evidenciado concepções sobre ordenamento território, na qual foi buscado autores que atestem a necessidade de vislumbrar o ambiente para tal feito.

A seção quarta realiza uma breve leitura da política ambiental brasileira, em especial, da Política Nacional de Meio Ambiente (BRASIL, 1981) por ser considerada um marco nacional na discussão da temática, relacionando-a com a dimensão do OT e, para isso, buscando em Steinberger e Abirached (2013) a fundamentação para discutir a política ambiental dotada de dimensão territorial, uma vez que essa possui contato com o território; e, por fim, são feitas as considerações acerca do conteúdo em tela.

\section{SÚMULA ACERCA DO MEIO AMBIENTE E DA QUESTÃO AMBIENTAL}

Dulley (2004), em sua investigação procurando melhor entender e diferenciar, do ponto de vista teórico, os conceitos de ambiente e meio ambiente, dente outros, coaduna para o esclarecimento destes termos, ou pelo menos incita o debate sobre. Primeiramente, entende-se que o ambiente é base para a promoção e regulação da vida.

Dulley (2004, p. 19) cita Gliessman (2000) quando este considera que o ambiente de um "organismo pode ser definido como a soma de todas as forças e fatores externo, tanto bióticos quanto abióticos, que afetam seu crescimento, sua estrutura e reprodução (...)”, sendo 
que esse ambiente necessita ser entendido com um conjunto dinâmico e sistêmico, em razão de seus componentes possuírem estreitas relações, sendo então constantemente modificado. Assim, o ambiente se constitui pelas condições que influenciam a vida, seja a da fauna, da flora e das sociedades.

Mendonça (2009), mencionando Bailly e Ferras (1997), compreende que, ao longo do tempo, o termo ambiente (ou meio ambiente) vem sendo modificado, principalmente pela inclusão do homem no seio das discussões, à medida que, inicialmente, este conceito foi vinculado a uma concepção mais naturalista dos seres vivos e seu habitat e, posterior, a sociedade figura como um agente transformador do ambiente. Sobremaneira, o conceito de meio ambiente ainda está "fortemente ligado a uma concepção naturalista, sendo que o homem socialmente organizado parece se constitui mais num fator que num elemento do meio" (MENDONÇA, 2009, p. 124).

Continuando a discussão, o autor supradito analisa que o termo meio ambiente, historicamente construído, parece não desvincular da perspectiva naturalista, haja vista que sua construção se inicia a partir de então. Assim, se torna um desafio incluir a abordagem social/econômico/político/cultural nessas discussões, no sentido de enxergar o homem como componente do meio e não apenas como um agente de transformação.

Segundo Suertegaray (2009), a inauguração do termo ambiental expressa a relação do ser com seu entono, sendo perceptível de forma individual e coletiva, naturalizada ou como também pelo reconhecimento de um ser social historicamente construído. Disto feito, o meio ambiente é entendido como possibilitador e resultado de complexas relações entre os seres historicamente construídas, como abordado por Mendonça (2009) e Suertegaray (2009).

Pode haver o meio constituído primordialmente pela natureza primária/primeira natureza, isto é, os elementos naturais bióticos e abióticos se inter-relacionam, sem a existência ainda de seres humanos modificando seu funcionamento (SUERTEGARAY, 2009), de mesmo modo, se percebe o ambiente construído mediante uma teia complexa de relações socioambientais, repercutindo em variados impactos. Esse ambiente tem como principal figurante o homem, em que suas ações, juntamente com às transformações naturais, tendem a modificar as características de uma natureza primária. 
O termo meio ambiente tem figurado nos debates contemporâneos que discutem a questão ambiental, refletindo sobre paradigmas do atual modelo de desenvolvimento ${ }^{1}$ das sociedades, os reflexos deste na natureza e os possíveis caminhos para que se possa minimizar os impactos ambientais ${ }^{2}$ e possibilitar a construção de modelos sustentáveis ${ }^{3}$ de convivência com o meio ambiente.

Para Porto-Gonçalves (2006), o mundo viu o aumento, especialmente na década de 1960, de um conjunto de movimentos, dentre eles os ecológicos/ambientais, que contestavam os (des)caminhos dados ao meio ambiente, que criticavam o modo de produção da época e, fundamentalmente, o modo de vida da população. Essas críticas, sobretudo ambientalistas, surgiram em um contexto internacional e se ampliaram, existindo desde então algumas exigências internacionais e obrigações institucionais para a validação de investimentos estrangeiros.

Na concepção de Custódio (2011, p. 82) a 'questão ambiental' emana de um conjunto de transformações globais em que seu início:

(...) temporal razoável é o século 18 , com a emergência da primeira Revolução Industrial, a configuração da escala mundo ensejada pelo capital e o fenômeno do processo de urbanização capitalista. É quando toma incremento, sem precedentes, a utilização da natureza primeira. Desde então, muitos foram os preocupados com as problemáticas atualmente consideradas como "ambientais", que, em verdade, são questões oriundas da contradição fundamental do modo de produção capitalista (...).

A autora salienta que, sobremaneira, a partir das décadas de 1960 e 1970 os problemas ambientais se tornaram 'questão ambiental', à medida que se percebeu uma série de transformações na natureza e na vida da população em todo mundo. Nesse sentido, acontecimentos como: o encarecimento da sustentação da matriz energética do petróleo, transformações na qualidade da vida urbana - problemas socioambientais urbanos -, a lógica reducionista do lucro e o consumo como meio de resolução de todos os problemas, o

\footnotetext{
${ }^{1}$ A ideia de desenvolvimemnto, geralmente, considera o crescimento econômico acompanhado da melhoria na qualidade de vida das pessoas. "O desenvolvimento deve buscar o alargamento de possibilidades de determinada sociedade [...] deve promover a ativação de recursos materiais e a mobilização de sujeitos sociais e políticos buscando ampliar o campo de ação da coletividade" (BRANDÂO, 2004, p. 14).

${ }^{2}$ Brasil (1986, p. 1) define impacto ambiental como "qualquer alteração das propriedades físicas, químicas e biológicas do meio ambiente, causada por qualquer forma de matéria ou energia resultante das atividades humanas".

${ }^{3}$ A sustentabilidade é uma concepção que afirma ser necessário ação racional de uso dos recursos ambientais, com vista a dar suporte à vida humana atual sem prejudicar as gerações futuras, proporcionando bem-estar para todos. Para Leff (2001, p.31) "o princípio de sustentabilidade surge como uma condição para construir uma nova racionalidade produtiva, fundada no potencial ecológico e em novos sentidos de civilização a partir da diversidade cultural do gênero humano".
} 
empobrecimento de pessoas dos países do Sul decorrentes da super exploração dos países do Norte, o super uso e comprometimento da natureza primeira de todo o planeta, acresceram os problemas ambientais (CUSTÓDIO, 2011).

Nesse contexto, gerou-se inúmeras manifestações que se diziam preocupadas com os rumos que se estavam dando aos recursos naturais, a exemplo do relatório Nosso Futuro Comum da Organização das Nações Unidas (ONU), de 1987, o qual discutindo problemáticas ambientais e indicando como solução para os problemas ambientais mundiais um desenvolvimento capitalista com equilíbrio ambiental, com harmonia entre homem e natureza (CUSTÓDIO, 2011).

Desse reflexo internacional de discussão sobre o ambiental, o Brasil incorpora em suas regulamentações legais entendimentos sobre a questão em voga, demostrando alinhamento a uma discussão mundial sobre o meio ambiente. Para além disso, cria diversas instituições com a finalidade de gerir o meio ambiente, mesmo ainda não havendo enraizamento dos movimentos ecológicos (PORTO-GONÇALVES, 2006).

Apesar de já haver discussões sobre as questões do meio ambiente, foi apenas em 1981 que se estabeleceu a Política Nacional do Meio Ambiente pela Lei $n^{\circ}$ 6.938. A PNMA define meio ambiente como "o conjunto de condições, leis, influências e interações de ordem física, química e biológica, que permite, abriga e rege a vida em todas as suas formas" (BRASIL, 1981, Art. $3^{\circ}$ ). Essa é uma das mais importantes leis em matéria de cuidado com o meio ambiente, estabelecendo mecanismos e instrumentos de preservação e de ordenamento territorial desse meio.

A PNMA, instrumento nato de ordenamento territorial brasileiro, tem por preceito a manutenção do meio ambiente equilibrado, devendo aos agentes que usam os recursos ambientais serem responsáveis por sua preservação, conservação ou revitalização. A PNMA entender por recursos ambientais: a atmosfera, as águas interiores, superficiais e subterrâneas, os estuários, o mar territorial, o solo, o subsolo, os elementos da biosfera, a fauna e a flora (BRASIL, 2008).

A Constituição Federal de 1988, Capítulo VI - Do Meio Ambiente - em seu Art. 225 afirma que "Todos têm direito ao meio ambiente ecologicamente equilibrado, bem de uso comum do povo e essencial à sadia qualidade de vida, impondo-se ao poder público e à coletividade o dever de defendê-lo e preservá-lo para as presentes e futuras gerações". 
Nesse sentido, o uso consciente do meio ambiente deve ter como agente a própria sociedade que faz uso deste, com a profícua finalidade de permitir que as futuras gerações possam dispor deste meio, já que o mesmo é visto como imprescindível a vivência social. Logo, todo e qualquer processo de degradação ambiental, interpretada como mudanças negativas no ambiente, que se refletem na perda da capacidade de suporte e da produtividade dos recursos naturais, tornou-se de responsabilidade de todos os cidadãos, não apenas do Estado (ARAÚJO, 2007).

Araújo (2007) ao citar Silva (1994) distingue a existência de três características do ambiente, sendo ele: natural, constituído pela biosfera e as relações reciprocas entre os elementos do meio físico-natural; cultural, constituído pelo patrimônio artístico, histórico, turístico, paisagístico, arqueológico e espeleológico; e o ambiente artificial, formado pelo ambiente urbano construído, concretado pelas edificações e equipamentos públicos. Essas dimensões do ambiente reforça a percepção de que este é onde ocorrem as interações. É onde o ser interage com aquilo que o cerca e que compreende o seu raio de integração.

Constatando que, em considerável parte dos casos, a interação homem-ambiente ocasiona processos degradativos, se faz necessário arbitrar sobre como essa integração [apropriação/uso] deve ocorrer. As deliberações e normatizações legais acerca da temática que orientam e impõem restrições sobre o uso dos recuros ambientais do território são construtos históricos que buscam contribuir com o ordenamento do território. Por conseguinte, as políticas ambientais são políticas fieis que coloboram com a realização do ordenamento territorial.

\section{O ORDENAMENTO TERRITORIAL ENQUANTO INSTRUMENTO E OBJETO DE GESTÃO}

No arranjo discursivo e prático necessário a manutenção do território está o ordenamento territorial, entendido como a(s) forma(s) de organização da extensão territorial, que objetive sua utilização racional e resolução de conflitos. Na Carta Europeia de Ordenamento Territorial - CEOT (1988, p. 9), o OT é um instrumento significativo no fortalecimento da identidade territorial, compreendido como o reflexo:

[...] espacial das políticas econômicas, social, cultural e ecológica da sociedade [...] é uma disciplina científica, uma técnica administrativa e uma política que se desenvolve numa perspectiva interdisciplinar e integrada tendente ao desenvolvimento equilibrado das regiões e a organização física do espaço segundo uma estratégia de conjunto (grifo nosso). 
Dado o exposto, compreende-se que OT, como mecanismo de ordenação, busca pensar o território como carente e cabível de ações capazes de articular os vários elementos que o compõe, a fim de chegar a um equilíbrio, promovendo o desenvolvimento. A CEOT nos apresenta que o OT, aliado a uma análise de desenvolvimento, capaz de reduzir disparidade regionais, promover melhor o uso e organização do espaço, distribuição das atividades, proteção do ambiente e melhoria na qualidade de vida.

Nesse sentido, o OT possui uma visão ampla de gestão do território, devendo ser considerado as tramas que fundamentam essas relações. Assim, Pujadas e Font (1998) compreendem que:

Ordenar consistirá em atribuir usos específicos e diferenciados num mosaico de
subdivisões [...] para o território fragmentado, objeto da ordenação [...] impulsionar o
desenvolvimento econômico, para melhorar a qualidade, para proteger o meio
natural, pois um critério a ser sempre considerado é o caráter limitado do território.
O território deve ser visto como um bem escasso, tanto em termos absolutos,
especialmente em termos de territórios que tenham alguma qualidade adicional [...]
está se enfatizando o caráter limitado e a escassês definitiva do território (PUJADAS;
FONT, 1998, - tradução de ALVES, 2014, p. 37) (grifo nosso).

Portanto, os autores suprastranscrito enfocam em uma perspectiva de avaliação das restrições do território como referência para organizá-lo, visto que esse mote é imprecindível ao entendimento holístico desse espaço a qual deseja se utilizar. Logo, para avaliar os recursos ambientais do território, é imprescindível reconhecer suas limitações de uso e potencialidades naturais, o que atenuará a crise dos recursos/crise ambiental.

Na percepção de Moraes (2005), o OT reveste-se de uma interpretação macro do espaço, focalizando grandes conjuntos espaciais (biomas, macrorregiões, redes de cidades) como espaços de interesse estratégico ou usos especiais (zona de fronteira, unidades de conservação, reservas indígenas, instalações militares, dentre outros).

Para o autor, o OT aborda o território em sua integridade e complexidade, à proporção que tenta abarcar sua estruturação, a demanda populacional e a gerência dos "fundos territoriais", isto é, compreender as potencialidade e fragilidade de seus recursos, o que demanda, então, ações competentes para seu uso, ocupação e proteção. Deste modo, o OT se torna um instrumento transetorial e interinstitucional, uma vez que possui como escopo um planejamento integrado e espacializado da atuação do poder público sobre o território (MORAES, 2005). 
Discorrendo sobre a Política Nacional de Ordenamento Territorial (PNOT), que foi apenas uma proposta em escala nacional, Moraes (Op. cit.) demonstra que a mesma deve manter-se solícita com as questões ambientais:

(...) seja em termos da identificação dos passivos ambientais existentes no território
usado, seja quanto ao uso futuro do patrimônio natural. Nesse particular, o conceito
de fundos territoriais deve ser incorporado como uma categoria central do
planejamento estratégico num país com as características geográficas do Brasil. A
riqueza natural brasileira precisa ser bem dimensionada em face dos planos de
desenvolvimento. (...). Enfim, diretrizes de planejamento ambiental estratégico
necessitariam constar da política em discussão (MORAES, 2005, p. 46) (grifo nosso).

Validando um panorama de inclusão da temática ambiental na efetivação do OT, o autor reconhece que essa política de gestão territorial deve manter-se preocupada com os recursos ambientais, já esses significam equilíbrio para esse recorte do espaço.

Santos (2005, p. 49) corrobora com a concepção acima ao afirmar que, historicamente, a política territorial brasileira vislumbrou-se no crescimento econômico e na infraestrutura correspondente, apropriando-se do "meio ambiente, acessório e aparentemente infinito na sua abundância, independentemente das consequências sobre a natureza", sendo posto uma lógica em que os mais "ricos e organizados impunham a força e a degradação correspondente, em detrimento da boa vizinhança e do respeito pelo patrimônio comum.” Se nota que as atribuições de responsabilidades de proteção do meio ambiente se tornam urgências, sendo aliado as outras metas para o desenvolvimento equilibrado e organização física do território.

Mediante leitura de Haesbaert (2006), para construir o OT se faz necessário reconhecer que o espaço geográfico é moldado ao mesmo tempo por forças econômicas, políticas, culturais ou simbólicas e naturais que se conjugam de formas profundamente diferenciadas e complexas em cada local, e isso se torna a dificuldade de construir o ordenamento do território. $\mathrm{O}$ autor discute que tentar ordenar é mesmo que "des-ordenar", visto que o território já possui uma ordem estabelecida. Ordenar é entrar em confronto com algo já territorializado, ou seja, construído no território.

Haesbaert (Op. cit.) continua sinalizando que o emaranhado de condições e as complexidades territoriais acabam por dificultar enormemente a construção das políticas de OT, que são, legitimamente, políticas de "des-ordenamento" territorial. O autor deixa evidente que as políticas de OT têm como desafio enfrentar a precarização socioespacial da população, e para isso, deve diminuir as desigualdades e exclusão socioeconômica da população; aumentar 
o nível de democratização e efetiva participação da população; fomentar o comprometimento público; trabalhar sempre o OT que integre múltiplas escalas.

Nesse segmento, nota-se que OT é um campo de conhecimento, um instrumento e uma política, o que expressa o enredo emblemático em compreendê-lo e efetivá-lo, logo, um tema caro para a sociedade. Para realizá-lo, se faz conveniente e imperativo a participação e articulação de/entre inúmeras escalas multidisciplinares, dado os inúmeros elementos que devem ser considerados ao pensar e propor o ordenamento territorial.

Questões como: diversidade e disparidades espaciais/regionais, decisões e intervenções no campo econômico, elaboração, implantação e avaliação de políticas públicas, análise e considerações das diversidades sociais e culturais, e ações interventivas sobre os recursos naturais, bem como suas complexas relações, são o mote para de fato ordenar o território. Esses elementos macros precisam ser considerados nesse processo, uma vez que são intrínsecos ao território.

A compreensão do OT deixa clara a multiescalaridade e multiinterdisciplinaridade imprescindível para realizar tal feito. Assim sendo, a dimensão ambiental também deve ser considerada. Nessa extensão, entender a relação estabelecida entre o homem e o meio, bem como os reflexos (impactos) disso, aliado a quais procedimentos mais conscientes seriam aconselhados, se torna um desafio. Pondera-se que o estudo dessa dimensão pode auxiliar no ordenamento territorial, uma vez que o estudo do meio ambiente pode auxiliar no uso e ocupação consciente desse.

Os estudos abordando o OT se encontram em expansão, sendo que este tem se configurado como importante ramo acadêmico, o que tem demandado a formação de profissionais vinculados a temática do planejamento territorial, com finalidade de pensar o território de maneira estratégica e racional, de modo que o organize, o desenvolva e o proteja (SILVA, 2013).

O OT, por essência, tem por pressuposto a regulação do espaço territorial, almejando garantir a qualidade de vida e o desenvolvimento sustentável de dada área. Essa concepção se aferve quando se enxerga que a introdução das técnicas humanas no meio natural causa uma série de problemáticas que necessitam ser resolvidas, quando pensado que o controle e equilíbrio do território se torna necessário para manter o desenvolvimento econômico, a igualdade social e a qualidade ambiental do meio. Desse modo, o diagnóstico do meio é base para sustentação do OT. 
Toda e qualquer ação de planejamento e ordenamento do território deve tomar como referência a análise do ambiente, de todas suas dimensões. Entender a dinâmica ambiental permanências e transformações - se torna uma necessidade perante o planejmaneto das ações humanas. Desse modo, o estudo do meio abiótico e biótico, das ocorrências de desastres e de suas susceptibilidades, dos riscos, da vulnerabilidade, da fragilidade e da capacidade de suporte dos ambientes, da ocupação humana e das dinâmicas decorrentes a partir de então, por exemplo, pode fornecer conhecimentos valorosos para embasar as decisões que resvalam no OT.

Destarte, para a efetivação do OT pressupõe, dentre outros segmentos, o planejamento ambiental e, para isso, se faz necessário o conhecimento holístico da área estudada em escala adequada, cabendo a análise detalhado dos elementos naturais e características históricas e necessidades socioeconômicas da população. Santos (2004) compreende que o diagnóstico do ambiente concebe um caminho a fim de compreender as potencialidades e as fragilidades das áreas definidas para estudo, da sua evolução, história, da ocupação e referente às pressões do homem sobre os sistemas ambientais.

Conhecer a dinâmica dos ambientes e os impactos antrópicos sobre eles é fator interveniente para sua utilização. Dado o expoxto, a necessidade de conservação e proteção dos recursos ambientais do território emerge. Como ela, a inserção de normatizações que buscam orientar as ações humanas e protecer tais recursos, como será visto na seção seguinte.

\section{PENSAR O MEIO AMBIENTE COM VISTA AO ORDENAMENTO TERRITORIAL: CASOS DE POLÍTICAS AMBIENTAIS BRASILEIRAS}

Nesta sessão, busca-se demonstrar que a política ambiental brasileira respeita o meio ambiente, resguardando sua proteção em suas regulamentações que contemplam o ordenamento do território. Salientamos que não se tratará da completude de todas as regulamentações, haja vista serem inúmeras, e não cabem ao momento. Compete dizer, também, mesmo não sendo objetivo desse trabalho, que o conjunto de leis se mostram incipiente ao que concerne a sua efetivação. O que a lei cria, em alguns momentos são desconsiderados pela sociedade, demostrando um descompasso entre regulação e cumprimento.

Até o momento, entende-se que as estratégias de ordenamento territorial possuem três níveis: o da legislação, no qual são traçados objetivos e instrumentos para o ordenar; o planejamento, dimensionado na elaboração dos planos e cenários futuros para o território; e 
execução, refletido nas ações pensadas a partir dos planos, sendo a prática para o implemento do OT (PUJADAS; FONT, 1998).

Nesse sentido, pensando as estratégias e ações de organização do território brasileiro, vinculando aqui a dimensão ambiental, o país tem construído um conjunto de políticas e planos que objetivam atender as demandas ambientais, isto é, comtemplar os ditos da questão ambiental em voga, na perspectiva da proteção, conservação e reversão da degradação dos recursos ambientais.

Tais instrumentos políticos reguladores do uso da natureza são, simultaneamente, reguladores do território, pois a política ambiental tem dimensão territorial, uma vez que esse é suporte para o que se intitula de meio ambiente (STEINBERGER; ABIRACHED, 2013). Vale a ressalva de que as políticas ambientais brasileiras são efetivas reguladora do território. Isso de deve porquê, geralmente, tais políticas são regulamentadas por legislações especificas - são leis -, o que é um avanço no que diz respeito a sua força de implementação e fiscalização.

Em uma breve retrospectiva da política ambiental brasileira, percebemos que essa inicia timidamente na década de 1930, com a criação do Código de Águas - Decreto nº 24.643/1934 - e o Código Florestal - Decreto no 23.793/1934 -, reformulada pela Lei nº 4.771/1965 e, posteriormente, substituída pela Lei $n^{\circ} 12.651 / 2012$, dispondo sobre a proteção da vegetação nativa. Sucedendo isto, foram concedidos outros instrumentos legais que buscam equalizar as demandas ambientais e as estratégias de desenvolvimento da sociedade.

Em leituras como as de Steinberger e Abirached (2013) e Moura (2016), é perceptível que entre as décadas de 1930 a 1970 tivemos regulamentações ambientais pontuais que tinham como foco a exploração dos recursos naturais, no entanto, não existia propriamente uma política ambiental no Brasil, bem como não havia uma instituição gestora da temática ambiental.

A partir de 1970, com a mundial efervescência da questão ambiental, que os motivos já foram expostos na sessão primeira deste texto, o Brasil acende na discussão sobre a temática, sendo criado o primeiro órgão que abordaria o meio ambiente em nível federal, a Secretaria Especial de Meio Ambiente (Sema), vinculada ao Ministério do Interior. De mesmo modo, alguns estados iniciaram a criação de seus órgãos estaduais de meio ambiente.

Como marco decisivo que discute a questão ambiental no Brasil, é evidenciado a Política Nacional de Meio Ambiente, criada em 1981 e regulamentada em 1990, criando o Sistema Nacional do Meio Ambiente (SISNAMA), sendo formado pelos órgãos e entidades da 
União, dos Estados, do Distrito Federal e dos Municípios responsáveis pela proteção, melhoria e recuperação da qualidade ambiental no país. A PNMA foi considerada inovadora para a época por dois motivos principais: por versar sobre um tema pouco discutido até então, e por ter caráter descentralizador ao distribuir as obrigações da gestão do meio ambiente para todos as entidades administrativas da União (MOURA, 2016).

A PNMA, em seu Art $2^{\circ}$, assinala que seu objetivo é a "preservação, melhoria e recuperação da qualidade ambiental propícia à vida, visando assegurar, no país, condições ao desenvolvimento socioeconômico, aos interesses da segurança nacional e à proteção da dignidade da vida humana".

Além da criação do SISNAMA, a Lei em evidencia criou o Conselho Nacional do Meio Ambiente (CONAMA), que tem natureza consultiva e deliberativa sobre o SISNAMA, possibilitando a participação pública nas discussões pertinentes à temática ambiental. Além disso, em seu Art. $9^{\circ}$, a PNMA instituiu os instrumentos da gestão ambiental, destacando-se: o estabelecimento de padrões de qualidade ambiental, o zoneamento ambiental, a avaliação de impactos ambientais, e o licenciamento de atividades efetiva ou potencialmente poluidoras. Esses instrumentos são intervenientes no território, posto que projetam obritariedades que devem ser executados por agentes competentes, com vistas a direcionar o controle das intervenções humanas sobre os recusos ambientais do território.

Nesse modo, para toda atividade que objetive utilizar os recursos ambientais, o poder público deveria utilizar desses instrumentos para mediar a gestão das ações propostas por agentes físicos ou jurídicos.

Steinberger e Abiracber (2013), discorrendo sobre a política ambiental brasileira, constroem um referencial no qual têm-se a PNMA como divisor de águas na discussão da questão ambiental, por discutirem temáticas até então nebulosas e não figuravam nos instrumentos normativos. Observe o quadro abaixo. 
Quadro 1: Principais temas ambientais do Brasil.

\begin{tabular}{|l|l|l|}
\hline \multicolumn{1}{|c|}{ Antes da PNMA } & \multicolumn{1}{|c|}{ Na PNMA (1981) } & \multicolumn{1}{c|}{ Após a PNMA } \\
\hline - Domínio de Uso das Águas & - Uso racional dos recursos & - Biodiversidade \\
- Proteção da Flora e Fauna & ambientais: solo, subsolo, ar e água & - Desmatamento \\
- Crimes e Contravenções & $-\quad$ Proteção dos ecossistemas & - Mudança no Clima \\
Florestais & - Poluição & \\
- Poluição Urbana e Industrial & $-\quad$ Qualidade ambiental & \\
& $-\quad$ Educação ambiental & \\
\hline
\end{tabular}

Fonte: einberger; Abirached (2013).

Na perspectiva analítica das autoras, a PNMA, a Política Nacional da Biodiversidade de 2002, o Plano para a Prevenção e Controle do Desmatamento na Amazônia Legal de 2004 e a Política Nacional sobre Mudanças do Clima de 2009, atualizam os temas da política brasileira de meio ambiente que condicionam aparatos legais que servem ao ordenamento territorial.

Compete salientar que tal atualização não significa que esses temas antes não haviam sido tratados, pelo contrário. Na história das ideias foram discutidos, no entanto, "são recentes porque foram objeto de diplomas legais específicos o que contribuiu para respaldar a intervenção do Estado brasileiro sobre tais temas ambientais" (STEINBERGER; ABIRACHED, 2013, p. 124).

Para além da PNMA, aqui destacamos outras regulamentações de relevância ambiental na manutenção dos "fundos territoriais", conceito proposto por Moraes (2005), que resvalam diretamente na organização e gestão do território. A Política Nacional de Recursos Hídricos, Lei ${ }^{\circ}$ 9.433/1997, baseada nos fundamentos de que a água é um bem de domínio público, sendo um recurso natural limitado, dotado de valor econômico.

Desse modo, a política tem por finalidade assegurar a disponibilidade hídrica à atual e às futuras gerações, bem como fomentar sua utilização racional, sendo executado maneiras de coordenar a gestão integrada das águas, a exemplo da criação dos Comitês de Bacias Hidrográficas, órgãos responsáveis por resolver conflitos, coordenar, planejar, regular e implementar o gerenciamento da água, articulado entre os diversos agentes. À vista disso, a referida lei ordena o território quando regula o gerenciamento dos recursos hídricos, de forma a orientar como os agentes do território devem agir perante a temática. 
Evidencia-se a Lei $n^{\circ} 9.985$, de 18 de julho de 2000, que institui o Sistema Nacional de Unidades de Conservação da Natureza - SNUC, estabelece critérios e normas para a criação, implantação e gestão das unidades de conservação. A lei compreende por unidade de conservação um espaço territorial e seus recursos ambientais, com características naturais relevantes com objetivos de conservação e limites definidos.

Nesse sentido, as unidades de conservação, dentre suas funções, objetivam resguardar a manutenção da diversidade biológica, proteger espécies ameaçadas de extinção, restauração da diversidade de ecossistemas naturais, proteger paisagens naturais de notória beleza cênica e proteger as características relevantes de natureza geológica, geomorfológica, espeleológica, arqueológica, paleontológica e cultural do território nacional. As unidades de conservação são exemplos claros de uma efetiva ação de/para o OT, ao passo que criam zonas especificas com restrições ambientais e legais, haja vista as peculiaridades que essas apresentam. Destarte, protegem os recusos ambientais e restringem as decisões humanas sobre o território.

A Lei $\mathrm{n}^{\mathrm{o}}$ 12.651, de 25 de maio de 2012, que, dentre outras providencias, estabelece normas gerais sobre a proteção da vegetação e das áreas de Preservação Permanente. Sendo a APP entendida como área protegida, coberta ou não por vegetação nativa, com a função ambiental de preservar os recursos hídricos, a paisagem, a biodiversidade, o solo, a estabilidade geológica, e assegurar o bem-estar das populações humanas.

Mediante a exposição de algumas constituintes da política ambiental brasileira, é possível relacionar a temática do ordenamento territorial, uma vez que tais instrumentos jurídicos foram pensados para mediar a relação da sociedade com sua base material, o território, e os elementos, "passivos ambientais", que o constitui.

Quando pensando o território como campo das relações sociais e que esse dispõe dos recursos naturais essenciais a sobrevivência e desenvolvimento da sociedade que nele vive, que dele usa, reportamo-nos a perspectiva teórica daqueles autores evidenciados anteriormente que consideram ser necessário ponderar a temática ambiental na execução das estratégias do ordenamento do território - o que se evidencia nas políticas assinaladas por este texto. A exemplo da criação das unidades de conservação ambiental e das áreas de preservação permanente, o que demostra a perspectiva restritivas sobre o território das regulamentações.

Mesmo que essas, em sua formulação, não tenham sido construídas com base no OT como arcabouço teórico, elas respondem muito bem ao que esse termo condiciona: regular o 
uso do território de forma a ordená-lo, organizá-lo, haja vista isto ser uma responsabilidade imprescindível da sociedade de modo geral.

\section{CONSIDERAÇÕES FINAIS}

É consenso que para o ordenamento do território, isto é, para sua organização, se faz indispensável a consideração, reflexão e atuação sobre os seus aspectos econômicos, políticos, sociais, culturais e ambientais, e tais aspectos tonam-se peculiares em cada território. Contudo, esse trabalho elegeu como mote para análise a dimensão ambiental.

Desse modo, ao pensar na política ambiental brasileira, que engloba a totalidade das intervenções do Estado sobre o meio ambiente, se afirma a maneira como os recursos naturais devem ser utilizados pelo homem, ponderando o desenvolvimento de suas atividades socioeconômicas e as capacidades e fragilidades ambientais.

Por conseguinte, reforçando a necessidade de uma consciência ambiental, com vista a inibir os riscos, isto é, a geração da degradação decorrente das ações humanas no ambiente. Nesse ínterim, se desenha o direto ambiental, constituído nos princípios jurídicos que se voltam para a proteção legal dos recursos naturais, visando a qualidade de vida da população, visto que as perturbações no meio impactam diretamente a sociedade. O objetivo dessa perspectiva é de harmonizar os eixos ecológicos, econômicos e sociais, buscando a preservação ambiental e proporcionado o bem-estar da população. Para isso, os instrumentos legais advogam em defesa do equilíbrio entre as limitações dos recursos naturais e as pretensões socioeconômicas da sociedade.

Percebe-se que a dimensão ambiental se torna cara para uma efetiva política de ordenamento territorial. Isso se manifesta nos instrumentos jurídicos que orientam e impõem limitações à atuação humana no ambiente. Isso se conforma, então, em uma política de base territorial, dado que os disciplinamentos são sobre o território. Logo, são medidas que orientam a execução de seu uso e regulação pela sociedade.

Em virtude dos aspectos apresentados, vale reforçar que as políticas ambientais possuem tênue contato com o território, o que as colocam como reguladoras de seu uso. Se executadas, são políticas que contribuem na promoção do ordenamento do território, a exemplo do PNMA, tida aqui como política nata de OT no Brasil. 


\section{REFERÊNCIAS}

ALVES, L. da S. F. Culturas de Ordenamento Territorial: conceituações e perspectivas histórico analíticas. Mercator, Fortaleza/CE, v. 13, n. 3, p. 63-73, set./dez. 2014. Disponível em: <http://www.mercator.ufc.br/mercator/article/view/1220>. Acesso em: 24 jan. 2020.

ARAúJO, L. A. Perícia Ambiental. In: GUERRA, A. J. T.; CUNHA, S. B. da (Orgs.). A questão Ambiental: diferentes abordagens. $3^{\text {a }}$ ed. Rio de Janeiro: Bertrand Brasil, 2007, p. 107-151.

BRANDÃO, C. A. Teorias, Estratégias e Políticas Regionais e Urbanas Recentes: anotações para uma agenda do desenvolvimento territorializado. Revista Paranaense de Desenvolvimento, Curitiba, n. 107, p. 57-76, jul./dez. 2004. Disponível em: <https://dialnet.unirioja.es/servlet/articulo?codigo=4813518>. Acesso em: 17 jan. 2021.

BRASIL. Conselho Nacional de Meio Ambiente (CONAMA). Resolução no 1, Dispõe sobre critérios básicos e diretrizes gerais para a avaliação de impacto ambiental. Brasília, 1986. DOU de 17 de fevereiro de 1986.

BRASIL. Lei $\mathbf{n}^{\circ}$ 6.938, de 31 de Agosto de 1981. Dispõe sobre a Política Nacional do Meio Ambiente, seus fins e mecanismos de formulação e aplicação, e dá outras providências. Presidência da República/Casa Civil. Brasília, em 31 de agosto de 1981.

BRASIL. Constituição da República Federativa do Brasil de 1988. Presidência da República/Casa Civil. Brasília, 5 de outubro de 1988.

BRASIL. Lei $n^{\circ}$ 9.433, de 8 de janeiro de 1997. Institui a Política Nacional de Recursos Hídricos, cria o Sistema Nacional de Gerenciamento de Recursos Hídricos, regulamenta o inciso XIX do art. 21 da Constituição Federal, e altera o $\operatorname{art.~}^{\circ}$ da Lei $\mathbf{n}^{\circ} 8.001$, de 13 de março de 1990, que modificou a Lei $n^{0}$ 7.990, de 28 de dezembro de 1989. Presidência da República/Casa Civil. Brasília, 1997.

BRASIL. Lei $\mathrm{n}^{\circ}$ 9.985, de 18 de julho de 2000. Regulamenta o art. 225, § 10, incisos I, II, III e VII da Constituição Federal, institui o Sistema Nacional de Unidades de Conservação da Natureza e dá outras providências. Presidência da República/Casa Civil. Brasília, 2000.

BRASIL. Ministério do Meio Ambiente. Legislação Ambiental Básica. Brasília: UNESCO, 2008.

CUSTÓDIO, V. Da questão ambiental à unanimidade do desenvolvimento sustentável. Paisagem Ambiente: ensaios, São Paulo/SP, n. 28, p. 79-94, 2011. Disponível em: <http://www.revistas.usp.br/paam/article/view/77388>. Acesso em: 30 ago. 2019

DULLEY, R. D. Noção de natureza, ambiente, meio ambiente, recursos, ambientais e recursos naturais. Agri. São Paulo, São Paulo/SP, v. 51, n. 2, p. 15-26, jul./dez., 2004. Disponível em:<http://www.iea.sp.gov.br/out/publicacoes/pdf/asp-2-04-2.pdf>. Acesso em: 15 ago. 2019. 
HAESBAERT, R. Ordenamento Territorial. Boletim Goiano de Geografia, Goiânia/GO, v. 26, n. 1, p. 117-124, 2006. Disponível em: <https://revistas.ufg.br/bgg/article/view/3572〉. Acesso em: 26 jun. 2018.

LEFF, E. Saber ambiental: sustentabilidade, racionalidade, complexidade, poder. Petrópolis, RJ: Vozes, 2001.

MENDONÇA, F. Geografia Socioambiental. MENDONÇA, F.; KOZEL, S. (Orgs.). Elementos de Epistemologia da Geografia Contemporânea. $1^{\text {a }}$ ed. rev. Curitiba/PR: Editora UFPR, 2009, p. 121-144.

MORAES, A. C. R. Ordenamento Territorial: uma conceituação para o planejamento estratégico. Para pensar uma política nacional de ordenamento territorial: anais da Oficina sobre a Política Nacional de Ordenamento Territorial, Brasília, 13-14 de novembro de 2003. Brasília: MI, 2005, p 43-46.

MOURA, A. M. M. de. Trajetória da política ambiental federal no Brasil. In: (Org.). Governança ambiental no Brasil: instituições, atores e políticas públicas. Brasília: Ipea, 2016, p. 13-44.

PORTO-GONÇALVES, C. W. Os (des)caminhos do Meio Ambiente. 14ª ed. São Paulo: Contexto, 2006.

PUJADAS, R. FONT, Jaume. Una aproximación conceptual a la Ordenación del Territorio. In__. Ordenación y Planificación Territorial. Madrid: España: Sintesis, 1998, p. 1140 .

SANTOS, T. C. Algumas considerações preliminares sobre Ordenamento Territorial. Para pensar uma política nacional de ordenamento territorial: anais da Oficina sobre a Política Nacional de Ordenamento Territorial, Brasília, 13-14 de novembro de 2003. Ministério da Integração Nacional, Secretaria de Políticas de Desenvolvimento Regional (SDR). Brasília: MI, 2005, p. 49-54.

SANTOS, R. Ferreira. Planejamento Ambiental: teoria e prática. São Paulo: Oficina de textos, 2004.

STEINBERGER, M.; ABIRACHED, C. F. A. Política ambiental: intervenção do Estado no uso da natureza e do território. In: STEINBERGER, M. (Org.). Território, Estado e políticas públicas espaciais. $1^{\mathrm{a}}$ ed. Brasília: Ler Editora, 2013, p. 115-140.

SUERTEGARAY, D. M. A. Geografia Física (?) Geografia Ambiental (?) ou Geografia e Ambiente (?). MENDONÇA, F.; KOZEL, S. (Orgs.). Elementos de Epistemologia da Geografia Contemporânea. $1^{a}$ ed. rev. Curitiba/PR: Editora UFPR, 2009, p. 111-120. 